\title{
Effect of Molybdenum Disulfide on the Performance of Polyaniline Based Counter Electrode for Dye-Sensitized Solar Cell Applications
}

\author{
Usman Ghafoor 1,*(D), Anas Bin Aqeel ${ }^{2}{ }^{(D}$, Uzair Khaleeq uz Zaman ${ }^{2}$, Taiba Zahid ${ }^{3}$, Muhammad Noman ${ }^{4}(\mathbb{D}$ and \\ Muhammad Shakeel Ahmad ${ }^{5, *(D)}$
}

1 Department of Mechanical Engineering, Institute of Space Technology, Islamabad 44000, Pakistan

2 Department of Mechatronics Engineering, College of Electrical and Mechanical Engineering, National University of Sciences and Technology, Islamabad 44000, Pakistan; anas.aqeel@ceme.nust.edu.pk (A.B.A.); uzair.khaleeq@ceme.nust.edu.pk (U.K.u.Z.)

3 Department of Mechanical Engineering, Capital University of Science and Technology, Islamabad 44000, Pakistan; taiba.zahid@cust.edu.pk

4 US-Pakistan Center for Advanced Studies in Energy, University of Engineering \& Technology, Peshawar 25000, Pakistan; muhammad.noman@uetpeshawar.edu.pk

5 Higher Institution Centre of Excellence (HICoE), UM Power Energy Dedicated Advanced Centre (UMPEDAC), Level 4, Wisma R\&D, University of Malaya, Jalan Pantai Baharu, Kuala Lumpur 59990, Malaysia

* Correspondence: usmanghafoor99@gmail.com (U.G.); shakeelalpha@gmail.com (M.S.A.)

check for updates

Citation: Ghafoor, U.; Aqeel, A.B.; Zaman, U.K.u.; Zahid, T.; Noman, M.; Ahmad, M.S. Effect of Molybdenum Disulfide on the Performance of Polyaniline Based Counter Electrode for Dye-Sensitized Solar Cell Applications. Energies 2021, 14, 3786. https://doi.org/10.3390/en14133786

Academic Editors: Jun-ichi Fujisawa, Hassan Elahi and Paolo Gaudenzi

Received: 24 April 2021

Accepted: 14 June 2021

Published: 24 June 2021

Publisher's Note: MDPI stays neutral with regard to jurisdictional claims in published maps and institutional affiliations.

Copyright: (c) 2021 by the authors. Licensee MDPI, Basel, Switzerland. This article is an open access article distributed under the terms and conditions of the Creative Commons Attribution (CC BY) license (https:/ / creativecommons.org/licenses/by/ $4.0 /)$.

\begin{abstract}
Dye-sensitized solar cells are gaining interest in the aerospace industry, extending their applications from solar-powered drones to origami-style space-based solar power stations due to their flexibility, light weightiness, and transparency. The major issue with its widespread commercial use is the employment of expensive Pt-based counter electrodes. In this study, an attempt has been made to replace the Pt with Polyaniline (PANI)/Molybdenum sulfide $\left(\mathrm{MoS}_{2}\right)$ nanocomposite. The nanocomposites i.e., PANI-0.5wt $\% \mathrm{MoS}_{2}$, PANI- $2 \mathrm{wt} \% \mathrm{MoS}_{2}, \mathrm{PANI}-5 \mathrm{wt} \% \mathrm{MoS}_{2}$, and PANI-7wt $\% \mathrm{MoS}_{2}$ and PANI-9wt $\% \mathrm{MoS}_{2}$, have been synthesized and compared with standard Pt-based CE. Scanning electron microscopy, transmission electron microscopy, and X-ray diffraction methods have been utilized to study both surface morphology and structural composition. Fourier transform infrared has also been used to identify redox-active functionalities. Electron impedance spectroscopy and cyclic voltammetry have been employed to study electron transfer and catalytic activity. Finally, I-V testing has been conducted using a sun simulator. A maximum efficiency of $8.12 \%$ has been observed with $7 \mathrm{wt} \% \mathrm{MoS}_{2}$ in the PANI matrix at $6 \mu \mathrm{m}$ thickness, which is $2.65 \%$ higher compared to standard Pt-based CE (7.91\%). This is due to high electronic conduction with the addition of $\mathrm{MoS}_{2}$, improved catalytic activity, and the high surface area of the PANI nano-rods.
\end{abstract}

Keywords: polyaniline; dye-sensitized solar cell; counter electrode; molybdenum disulfide; catalyst

\section{Introduction}

The technology of DSSC has attained immense attention in the scientific community as a promising future photovoltaic due to its ease in fabrication, optimum efficiency, costeffectiveness, environment-friendly manufacturing, and optimum life span [1]. Effectively extending its applications from portable electronic devices to building integrated systems, solar-powered drone applications have a huge potential to be explored in the field of space technology as flexible origami-style solar power stations and for easy lift-off, even in confined areas of space crafts and rockets [2]. The DSSC device is essentially a sandwich structure consisting of a semi-conductor light-harvesting layer (mostly $\mathrm{TiO}_{2}$ ), dye sensitizer, electrolyte, and a catalyst layer (mostly $\mathrm{Pt}$ ), sandwiched between two conducting substrates (mostly FTO coated glass). In principle, the sunlight is absorbed by the dye sensitizer and 
becomes oxidized. The ejected electron is then picked by the semi-conductor layer and transferred to the outer circuit through a conducting substrate. The oxidized dye takes an electron from the electrolyte which has been further reduced by an incoming outer electron with the help of a catalyst. This process of regeneration keeps occurring until the sunlight is present [3-5].

The rare earth element $\mathrm{Pt}$ has proved to be the most effective and efficient catalyst for DSSC, being coated on a counter electrode (in brief, a counter electrode is any conducting substrate coated with a suitable catalyst). The counter electrode acts as a cathode, which is responsible for accepting electrons from the outer circuit and regenerating electrolytes. The limited availability and expensive nature of Pt limits the use of DSSC technology and is probably one of the main hurdles in the commercialization of this technology [6,7]. Various materials and their combinations have been tried to replace $\mathrm{Pt}$ with promising results. In this regard, conducting polymers such as polyaniline, polypyrrole, poly(3,4-ethylenedioxythiophene, etc., have shown encouraging electronic and catalytic properties [8].

Among conducting polymers, PANI and its nanocomposites with various inorganic materials such as $\mathrm{Au}$ [9], $\mathrm{Al}$ [10], and other transition metals [11] have been investigated and the results have revealed comparable electronic and catalytic properties. Other advantages include low-cost synthesis, low-temperature coating, and ease in availability of raw materials. In one study, porous PANI nanotubes were investigated as a counter electrode. The claimed efficiency of porous PANI as a counter electrode was 5.57\% (at optimized layer thickness), which is higher compared to standard reference Pt-based CE (5.20\%) [12]. In another study, PANI was doped with reduced grapheme nano sheets with comparable results [13]. In a recent study, a combination of polyacrylonitrile/polyaniline/tungsten dioxide was investigated, which increased catalytic activity in the iodide/triiodide electrolyte [14]. Recently, PANI was doped with molybdenum diselenide and its effects were investigated as a counter electrode for DSSC. The remarkable overall conversion efficiency of $8.04 \%$ and the high cathodic current density in the iodide/triiodide electrolyte has been claimed to be $4.68 \%$ higher compared to the standard Pt-based CE [15].

Recently, a $\mathrm{MoS}_{2}$ transparent thin film has been deposited on FTO glass using both one-step potentiostat and potential-reversal electrodeposition methods. This film has been employed as a counter electrode for the bifacial DSSC device. The highest efficiency of $8.77 \%$ has been claimed, which is close to the standard Pt-based CE [16]. Herein, we synthesized $\mathrm{PANI} / \mathrm{MoS}_{2}$ nanocomposites with varying $\mathrm{MoS}_{2}$ concentrations in order to investigate the effect of $\mathrm{MoS}_{2}$ concentration in the PANI matrix. The oxidation polymerization method has been employed in order to synthesize the PANI nano-rods. A simple solution mixing method has been used to prepared nanocomposites and a heat-assisted drop-casting method has been employed to fabricate CE specimens.

\section{Experimental Investigation}

\subsection{Polyaniline Nano-Rods (PANI) Synthesis}

Conducting polyaniline (emeraldine salt) was prepared using chemical oxidation method mentioned in the literature [17]. Briefly, a certain amount of monomer of aniline $(0.0215 \mathrm{~mol})$ was treated with a certain amount of $\mathrm{HCl}(30 \mathrm{~mL})$ solution with a 1 molar aq concentration. The ammonium peroxydisulfate (acting as an oxidant) was added to the solution of aniline and $\mathrm{HCl}$ and stirred continuously below $5{ }^{\circ} \mathrm{C}$ using a magnetic stirrer for $3 \mathrm{~h}$. The solution was filtered and dried at $60^{\circ} \mathrm{C}$ overnight. The dry greenish powder was then stored in a refrigerator until further use.

\subsection{Preparation of PANI-MoS $\mathrm{S}_{2}$ Nanocomposite}

The PANI and $\mathrm{MoS}_{2}$ nanocomposites were prepared using a simple chemical mixing method. In brief, powder PANI was suspended in de-ionized water using ultrasonication and stirred for $3 \mathrm{~h}$ at room temperature. A certain amount of $\mathrm{HCl}$ was added to the suspension followed by an introduction of $\mathrm{MoS}_{2}$ into the suspension with continuous stirring for further $5 \mathrm{~h}$. The mixture was centrifuged and washed using de-ionized water five times, 
followed by drying at $60^{\circ} \mathrm{C}$ overnight. All of the samples with varying concentrations were prepared using the same procedure.

\subsection{Counter Electrode Fabrication}

The CEs have been prepared using drop casting method. A stable ink was prepared using a suitable solvent (toluene) and binder (polystyrene) in $70 \mathrm{wt} \%$ and $3 \mathrm{wt} \%$ concentrations with respect to the $\mathrm{wt} \%$ of nanocomposite. To cast the ink, the fluorine doped tin oxide (FTO) glass was washed properly using ethanol and masked with a $6 \mu \mathrm{m}$ high-density polyethylene (HDPE) film with a $1 \times 1 \mathrm{~cm}^{2}$ window. The masked FTO glass was placed over the heating plate and the temperature was set to $60^{\circ} \mathrm{C}$ prior to drop casting. The ink was drop-casted slowly using a medical syringe and the temperature was raise to $90{ }^{\circ} \mathrm{C}$ and maintained for $1 \mathrm{~h}$ after the casting. After that, the temperature was raised to $120^{\circ} \mathrm{C}$ and the samples were kept at the same temperature for $1 \mathrm{~h}$ for proper drying and crack-free coating. All of the samples were prepared using the same method. For comparison, the $\mathrm{Pt}$ coated FTO glass was prepared using Pt paste and annealed to $450{ }^{\circ} \mathrm{C}$ for $1 \mathrm{~h}$.

\subsection{DSSC Fabrication}

To prepare an efficient DSSC device, great care was practiced for the fabrication of a photoanode. A layered approach was used to fabricate high efficiency photoanode. In brief, FTO glass was washed using ethanol and dried in oven. After that, the FTO glass was immersed in $\mathrm{TiCl}_{4}$ solution and annealed at $400{ }^{\circ} \mathrm{C}$ for $30 \mathrm{~min}$. The $\mathrm{TiCl}_{4}$ treated FTO glass was coated with $\mathrm{TiO}_{2}(\mathrm{P} 25)$ paste and annealed at $450{ }^{\circ} \mathrm{C}$ for $1 \mathrm{~h}$. The as0prepared coated glass was again treated with $\mathrm{TiCl} 4$ solution and annealed for another $30 \mathrm{~min}$ at $400{ }^{\circ} \mathrm{C}$. This procedure created a blocking layer that would minimize the recombination reactions. The now prepared samples were again coated with $\mathrm{TiO}_{2}$ paste with coarse $\mathrm{TiO}_{2}$ particles and annealed at $450{ }^{\circ} \mathrm{C}$ for $1 \mathrm{~h}$. This layer of coarse $\mathrm{TiO}_{2}$ particles would improve the high scattering ability and improve the light harvesting capability of photoanode. The samples were again treated with $\mathrm{TiCl}_{4}$ to create a blocking layer.

The prepared photoanodes were immersed in Ru(dcbpy)2(NCS)2 (dcbpy $\frac{1}{4}$ 2,2-bipyridyl4,4-dicarboxylato) dye solution (535-bisTBA (N719), Solaronix) with acetonitrile overnight and rinsed with DI water. The prepared counter electrode was placed over the dye impregnated photoanode and sealed by heating after placing a hot melt film between them. Electrolyte Z-150 was filled using a medical syringe and sealed using hot glue. It is worth mentioning here that five specimens for each DSSC device were prepared and testing using the same conditions. The mean value for $V_{o c}, I_{s c}$ and the efficiency has been presented through the manuscript.

\subsection{Characterization}

The morphological and phase identification (composition) analysis was performed using scanning electron microscopy (SEM) and X-ray diffraction (XRD). A Fourier transformed infrared (FTIR) study has also been conducted to examine the chemical groups and nature of the bonds. For the electrochemical studies, cyclic voltametery (CV) and electrochemical impedance spectroscopy were conducted. The CV was conducted in a three-electrode setup where the counter electrode was $\mathrm{Pt}$ wire, the reference electrode was $\mathrm{Ag} / \mathrm{AgCl}$, and the as-prepared electrodes were used as working electrodes. The range of electrical potential was set from -1.0 to $1.0 \mathrm{~V}$ with an optimized scan rate of $20 \mathrm{mVs}^{-1}$. The frequency range of $0.1-1 \mathrm{MHz}$ was used for the EIS studies. The I-V characteristics, $V_{o c}$ and $I_{s c}$, have been measured using a solar simulator at a $1000 \mathrm{~W} / \mathrm{m}^{2}$ irradiation level.

\section{Results and Discussion}

Figure 1a,b illustrates the SEM images of the as-synthesized PANI nano-rods and as-received $\mathrm{MoS}_{2}$ nanoparticles. A solid rod-like morphology of the PANI is evident from Figure 1a, along with a rough surface. The approximate diameter of the PANI nano-rod ranged between 50 and $90 \mathrm{~nm}$. The length ranged from between $500 \mathrm{~nm}$ to more than $2 \mu \mathrm{m}$. 
On the other hand, the SEM image of the raw $\mathrm{MoS}_{2}$ shows irregular sheet-like morphology along with smooth surfaces. The $\mathrm{MoS}_{2}$ sheets size ranged between 200 and $800 \mathrm{~nm}$ and the thickness of $\mathrm{MoS}_{2}$ sheets ranged between 20 and $50 \mathrm{~nm}$.
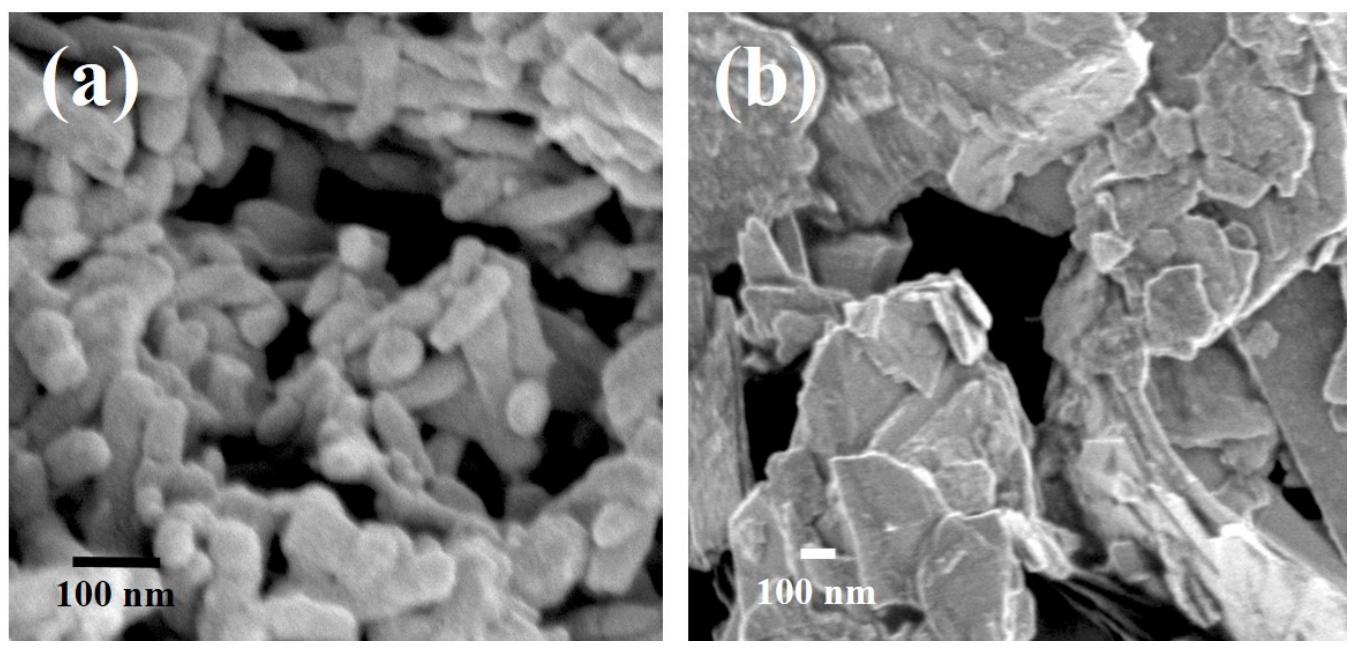

Figure 1. SEM micrographs of (a) as-synthesized PANI nano-rods and (b) as-received $\mathrm{MoS}_{2}$ nanosheets.

Figure $2 \mathrm{a}, \mathrm{b}$ shows the SEM and TEM images of the highest performing nanocomposite (i.e., PANI $/ 7 w t \% \mathrm{MoS}_{2}$. Figure $2 \mathrm{a}$ shows homogenous mixing of two phases while TEM was conducted in order to examine the internal structure of the nanocomposite. No contrast through the thickness was observed for PANI, which suggests a solid rod-like internal structure. The XRD pattern of PANI/7wt \% MoS 2 is shown in Figure 2c. The peaks at close to 25 2-theta values represent the PANI phase. On the other hand, the 2 theta peaks at 30, 45, and 60 represent the $\mathrm{MoS}_{2}$ phase. Note that the XRD of the best performing specimen has been presented here. The XRD patterns of bare PANI, PANI- $0.5 \mathrm{wt} \% \mathrm{MoS}_{2}, \mathrm{PANI}-$ $2 \mathrm{wt} \% \mathrm{MoS}_{2}, \mathrm{PANI}-5 \mathrm{wt} \% \mathrm{MoS}_{2}$, and PANI-9 $\mathrm{wt} \% \mathrm{MoS}_{2}$ are presented in Figures S1-S5, respectively, and in the Supplementary Materials. The FTIR (Figure S6) was conducted in the range of $500-4500 \mathrm{~cm}^{-1}$. The convoluted set of peaks between 1000 and $1500 \mathrm{~cm}^{-1}$ shows a mix of stretching and bending modes of $\mathrm{C}-\mathrm{C}, \mathrm{C}-\mathrm{O}$, and $\mathrm{C}-\mathrm{H}$ functionalities. The result most interesting to the present study is the presence of redox-active functionalities, such as unsaturated ketones or quinone-like moieties $\left(1600-1700 \mathrm{~cm}^{-1}\right)$, that can participate in redox cycling [18].

Figure 3 shows the current voltage curves of specimens under investigation. The detailed summary of parameters has been presented in Table 1. It was observed that with the incorporation of $\mathrm{MoS}_{2}$ nanosheets in the PANI matrix of CE, the overall photoconversion efficiency increased. The PANI/2wt $\% \mathrm{MoS}_{2}$ CE-based DSSC device exhibited a conversion efficiency of $7.73 \%$ along with values of $V_{o c}$ and $I_{S C}$ as $0.61 \mathrm{~V}$ and $15.36 \mathrm{~mA} / \mathrm{cm}^{2}$, respectively, which is 3.62\% higher compared to bare PANI CE based DSSC. The addition of $5 \mathrm{wt} \% \mathrm{MoS}_{2}$ in PANI led to a further increase in efficiency (by 7.98\%). The best performance was achieved at 7wt $\% \mathrm{MoS}_{2}$. The PANI/7wt $\% \mathrm{MoS}_{2}$ CE-based DSSC exhibited a remarkable $8.12 \%$ conversion efficiency along with values of $V_{O C}$ and $I_{S C}$ as $0.62 \mathrm{~V}$ and $17.24 \mathrm{~mA} / \mathrm{cm}^{2}$. This efficiency is $8.84 \%$ higher compared to the bare PANI CE-based DSSC and $2.65 \%$ higher compared to the Pt CE-based reference DSSC. A further increase in the concentration of $\mathrm{MoS}_{2}$ in PANI led to a reduction in overall efficiency. This may be due to an increase in defects and electron trapping sites. 

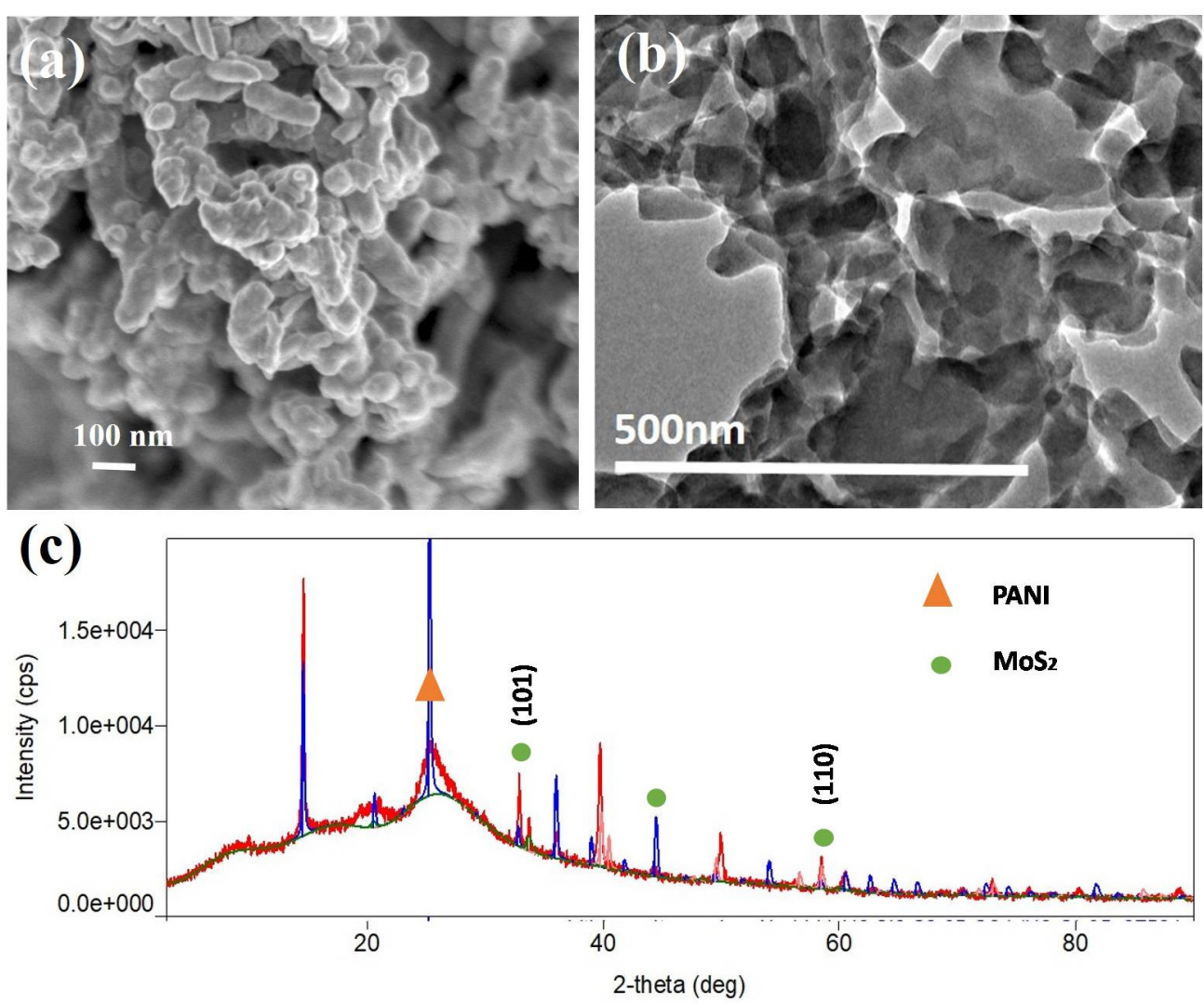

Figure 2. (a) SEM micrograph of PANI-7wt $\% \mathrm{MoS}_{2}$, (b) TEM micrograph of PANI-7wt $\% \mathrm{MoS}_{2}$, and (c) XRD pattern of PANI-7wt\% $\mathrm{MoS}_{2}$ (JCPDS NO. 00-032-0671 $\left(\mathrm{MoS}_{2}\right)$ ).

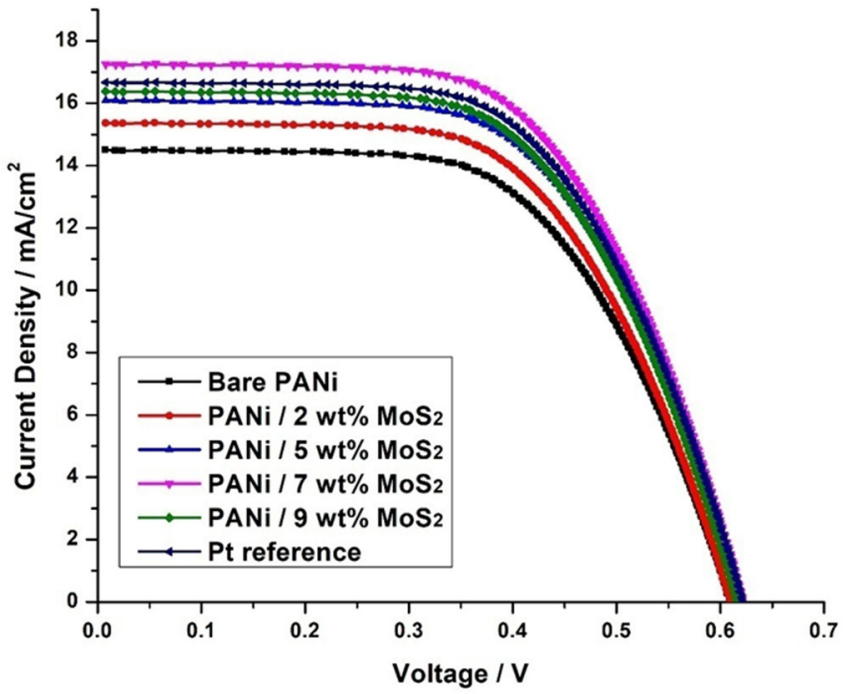

Figure 3. Current-voltage curves of specimens under investigation.

To understand the increasing trend in conversion efficiency with the addition of $\mathrm{MoS}_{2}$ in PANI, a CV of all the nanocomposites was performed, along with the bare PANI and Pt for comparison purposes. Figure 4 shows the cyclic voltammograms of the specimens under investigation. Iodolyte Z-150 (0.01 M concentration in acetonitrile) electrolyte was used for the CV. Redox peaks for each curve can be observed in Figure 3, suggesting a reduction of $I_{3}^{-}$to $I^{-}$(left side) and oxidation of $I^{-}$to $I_{3}^{-}$(right side). The equation presented in Figure 3 represents a reduction reaction. It is well known that the performance of DSSC is directly related to the electrocatalytic activity of catalysts towards the reduction 
of $I_{3}^{-}$. High cathodic current density suggests faster kinetics of the electrocatalytic process of electrodes [19]. An increase in redox peaks was observed with the introduction of $\mathrm{MoS}_{2}$ in PANI, suggesting an increase in the catalytic activity of the PANI matrix with the addition of $\mathrm{MoS}_{2}$. A further increase in the concentration of $\mathrm{MoS}_{2}$ led to an increase in redox peaks. The PANI $/ 7 \mathrm{wt} \% \mathrm{MoS}_{2}$ nanocomposite exhibited the highest redox peaks, outperforming the bare PANI and Pt references. The CV results correspond with the I-V curves and overall efficiency, which are in agreement with each other. It can be said with confidence that the increase in overall conversion efficiency was due to an increase in the catalytic activity of PANI/MoS 2 nanocomposite which led to an increase in the current density of the DSSC device.

Table 1. A detailed summary of I-V parameters.

\begin{tabular}{cccccc}
\hline Sr. No. & Specimen ID & $\boldsymbol{V}_{\boldsymbol{o c}} \mathbf{( V )}$ & $\boldsymbol{I}_{\boldsymbol{s c}} \mathbf{( \mathbf { m A } / \mathbf { c m } ^ { \mathbf { 2 } } )}$ & $\mathbf{F F} \mathbf{( \% )}$ & EFF (\%) \\
\hline 1 & PANI CE based DSSE & 0.61 & 14.49 & 71 & 7.46 \\
2 & PANI-2wt\% $\mathrm{MoS}_{2}$ CE based DSSC & 0.61 & 15.36 & 72 & 7.73 \\
3 & PANI-5wt $\mathrm{MoS}_{2}$ CE based DSSC & 0.62 & 16.08 & 71 & 7.98 \\
4 & PANI-7wt $\% \mathrm{MoS}_{2}$ CE based DSSC & 0.62 & 17.24 & 73 & 8.12 \\
5 & PANI-9wt\% $\mathrm{MoS}_{2}$ CE based DSSC & 0.61 & 16.37 & 72 & 7.87 \\
6 & Pt reference & 0.62 & 16.68 & 74 & 7.91 \\
\hline
\end{tabular}

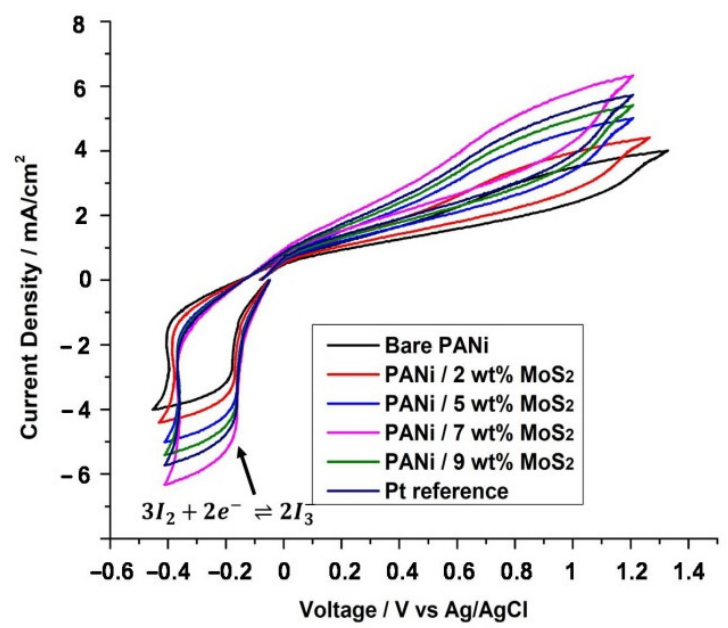

Figure 4. Cyclic voltammograms of specimens under investigation.

To further study the electron kinetics and their effect on the overall charge transfer resistance, an EIS was performed. Figure 5 shows the EIS pattern of specimens under investigation. Three semi-circles are evident for each specimen from high frequency to low frequency. The first semi-circle at high frequency represents the charge transfer properties (Faraday's redox reaction resistance) at the counter electrode (catalyst/electrolyte interface) which is the main focus of the present study. The second semi-circle represents electron kinetics at the interfaces present at photoanode (i.e., the nano-architecture $\left(\mathrm{TiO}_{2}\right) /$ dye/electrolyte interface). The third semi-circle belongs to the Warburg diffusion process of iodide ions in the electrolyte. The graph has been adjusted on ZVIEW software and drawn against an imaginary axis. The equivalent circuit is shown in Figure 5. The onset point of the first semicircle at the high-frequency range represents the series resistance $\left(R_{s}\right)$ and its radius refers to the charge transfer resistance $\left(R_{c t}\right)$ which corresponds to the catalytic process at the film/electrolyte interface. A negative shift in $R_{s}$ and $R_{c t}$ values has been observed that, with the addition of the $\mathrm{MoS}_{2}$ nano-sheets in PANI, imply a reduction of the overall charge transfer resistance. The lowest $R_{s}$ and $R_{c t}$ values have been displayed by the PANI $/ 7 \mathrm{wt} \% \mathrm{MoS}_{2}$ nanocomposite, outperforming the reference Pt CE. A further increase in the concentration of $\mathrm{MoS}_{2}$ led to an increase in the charge transfer resistance, which can be co-related with the CV and I-V results. 


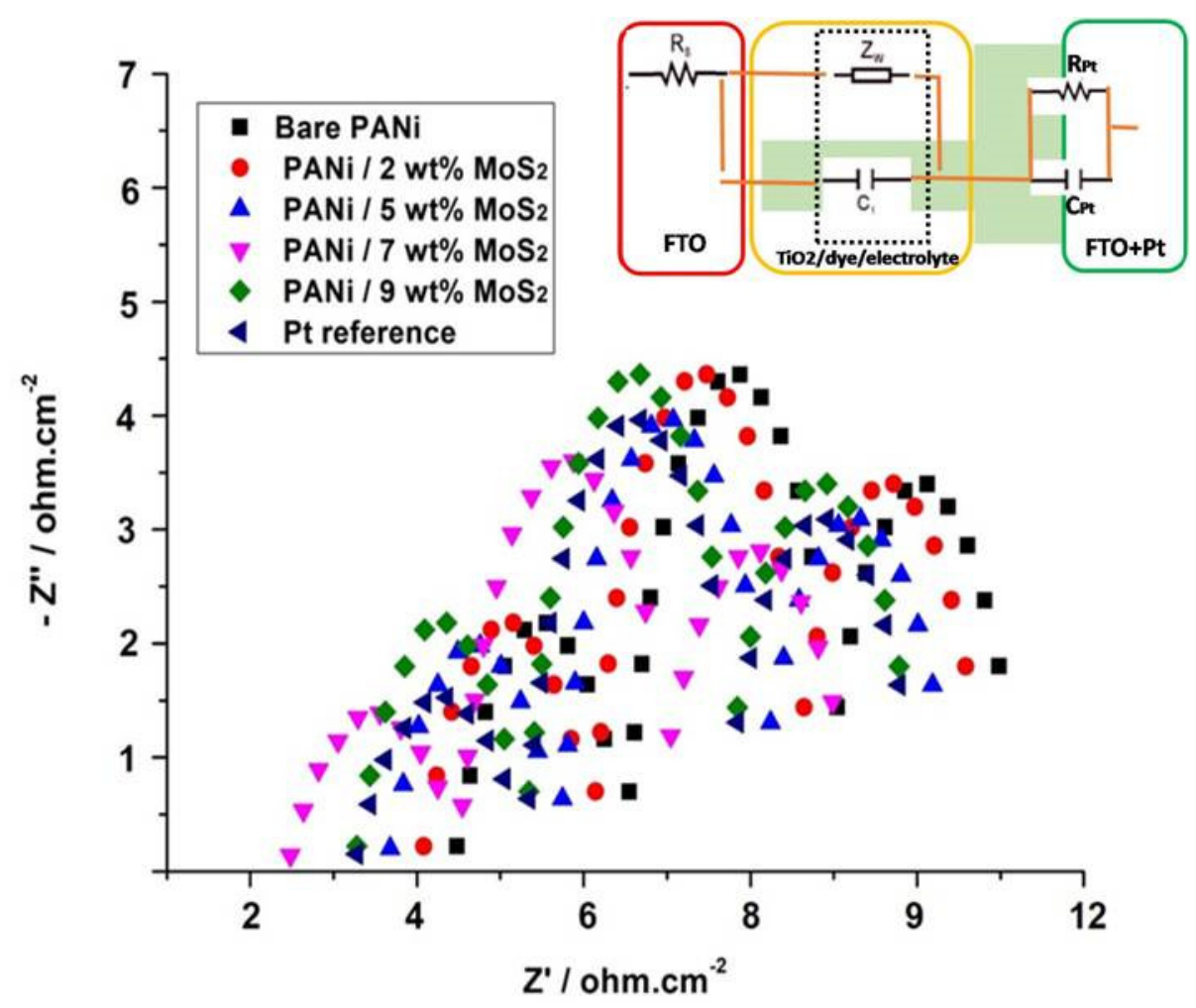

Figure 5. EIS pattern of specimens under investigation.

The increase in resistance led to a reduction in current density, which affected the overall conversion efficiency. The EIS results are in agreement with the CV and I-V results presented in Figures 3 and 4 . The best performance exhibited by PANI/7wt $\% \mathrm{MoS}_{2} \mathrm{CE}-$ based DSSC was due to high catalytic activity, optimum available catalytic cites, and high electron transfer ability, which led to an increase in the current density of the DSSC device.

\section{Conclusions}

The high achievable module flexibility, low cost, lightweight nature, and ability of DSSC to harvest indoor light make it a potential candidate to be used in aerospace technologies such as electrically operated solar-powered drones, lightweight portable structures (such as origami-style space solar power stations), and the powering of highaltitude blimps. In this study, the effect of $\mathrm{MoS}_{2}$ on the catalytic and charge transfer ability of PANI-based CE has been investigated. SEM and XRD methods have been utilized to study both surface morphology and structural composition. EIS and CV have been employed to study the electron transfer and catalytic activity, respectively. Finally, I-V testing has been conducted using a sun simulator. A maximum efficiency of $8.12 \%$ was observed with $7 \mathrm{wt} \% \mathrm{MoS}_{2}$ in the PANI matrix at a $6 \mu \mathrm{m}$ thickness, which is $2.65 \%$ higher compared to the standard Pt-based CE (7.91\%). This is due to high electronic conduction with the addition of $\mathrm{MoS}_{2}$, improved catalytic activity, and the high surface area PANI. The proposed CE material has the potential to replace Pt-based CEs due to its cost-effectiveness, chemical inertness, and ease in fabrication.

Supplementary Materials: The following are available online at https: / www.mdpi.com/article / 10.3390 /en14133786/s1, Figure S1. Bare PANI coated on glass substrate, Figure S2. PANI-0.5wt $\%$ MoS2 coated on glass substrate, Figure S3. PANI-2wt $\%$ MoS2 coated on glass substrate, Figure S4. PANI-7wt $\%$ MoS2 coated on glass substrate, Figure S5. PANI-9wt $\%$ MoS2 coated on glass substrate, Figure S6. FTIR spectra of pure PANI and PANI/7wt $\%$ MoS2 composite.

Author Contributions: Conceptualization, M.S.A. and U.G.; formal analysis, M.S.A. and M.N.; funding acquisition, A.B.A. and U.K.u.Z.; investigation, T.Z.; methodology, M.N.; project adminis- 
tration, T.Z.; resources, U.G.; validation, A.B.A. and U.K.u.Z.; writing—original draft, M.S.A. and U.G.; writing-review \& editing, T.Z. All authors have read and agreed to the published version of the manuscript.

Funding: The authors thank the financial assistance of the Higher Institution Centre of Excellence (HICoE) Program Research Grant, UMPEDAC—2020 (MOHE HICOE-UMPEDAC), Ministry of Education Malaysia, TOP100UMPEDAC, RU003-2020, University of Malaya.

Institutional Review Board Statement: Not applicable.

Informed Consent Statement: Not applicable.

Data Availability Statement: The prepared samples to support the findings of this study are available from the corresponding authors upon reasonable request.

Acknowledgments: The authors would like to thank the technical assistance of the UM Power Energy Dedicated Advanced Centre (UMPEDAC), University of Malaya and Department of Mechanical Engineering, Institute of Space Technology, Islamabad, Pakistan.

Conflicts of Interest: The authors declare no conflict of interest.

\section{References}

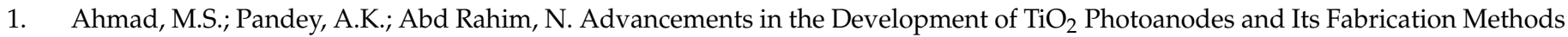
for Dye Sensitized Solar Cell (Dssc) Applications. A Review. Renew. Sustain. Energy Rev. 2017, 77, 89-108. [CrossRef]

2. Lee, C.P. Ultralight Paper-Based Electrodes for Energy Applications. In Novel Nanomaterials: Synthesis and Applications; IntechOpen: Rijeka, Croatia, 2018; p. 257.

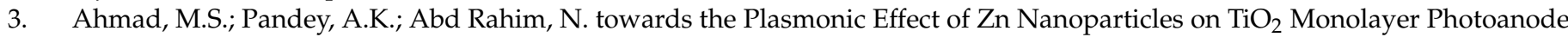
for Dye Sensitized Solar Cell Applications. Mater. Lett. 2017, 195, 62-65. [CrossRef]

4. Ahmad, M.S.; Pandey, A.K.; Abd Rahim, N. Effect of Nanodiamonds on the Optoelectronic Properties of Tio \$\$_ \{\} \$ Photoanode in Dye-Sensitized Solar Cell. Arab. J. Sci. Eng. 2018, 43, 3515-3519. [CrossRef]

5. Chalkias, D.A.; Charalampopoulos, C.; Aivali, S.; Andreopoulou, A.K.; Karavioti, A.; Stathatos, E. A Di-Carbazole-Based Dye as a Potential Sensitizer for Greenhouse-Integrated Dye-Sensitized Solar Cells. Energies 2021, 14, 1159. [CrossRef]

6. Ahmed, U.; Alizadeh, M.; Abd Rahim, N.; Shahabuddin, S.; Ahmed, M.S.; Pandey, A.K. A Comprehensive Review on Counter Electrodes for Dye Sensitized Solar Cells: A Special Focus on Pt-Tco Free Counter Electrodes. Sol. Energy 2018, 174, $1097-1125$. [CrossRef]

7. Kim, J.; Jung, S.; Kim, H.J.; Kim, Y.; Lee, C.; Kim, S.M.; Kim, D.; Jun, Y. Sinw /C@ Pt Arrays for High-Efficiency Counter Electrodes in Dye-Sensitized Solar Cells. Energies 2020, 13, 139. [CrossRef]

8. Gunasekera, S.S.B.; Perera, I.R.; Gunathilaka, S.S. Conducting Polymers as Cost Effective Counter Electrode Material in DyeSensitized Solar Cells. In Solar Energy; Springer: Singapore, 2020; pp. 345-371.

9. Ghani, S.; Sharif, R.; Bashir, S.; Ashraf, A.; Shahzadi, S.; Zaidi, A.A.; Rafique, S.; Zafar, N.; Kamboh, A.H. Dye-Sensitized Solar Cells with High-Performance Electrodeposited Gold/Polyaniline Composite Counter Electrodes. Mater. Sci. Semicond. Process. 2015, 31, 588-592. [CrossRef]

10. Tas, R.; Can, M.; Sonmezoglu, S. Exploring on Photovoltaic Performance of Dye-Sensitized Solar Cells Using Polyaniline as a Counter Electrode: Role of Aluminum-Solvent Interactions. IEEE J. Photovolt. 2017, 7, 792-801. [CrossRef]

11. Wu, K.; Chen, L.; Sun, X.; Wu, M. Transition-Metal-Modified Polyaniline Nanofiber Counter Electrode for Dye-Sensitized Solar Cells. ChemElectroChem 2016, 3, 1922-1926. [CrossRef]

12. Park, K.H.; Kim, S.J.; Gomes, R.; Bhaumik, A. High Performance Dye-Sensitized Solar Cell by Using Porous Polyaniline Nanotubes as Counter Electrode. Chem. Eng. J. 2015, 260, 393-398. [CrossRef]

13. Mehmood, U.; Karim, N.A.; Zahid, H.F.; Asif, T.; Younas, M. Polyaniline/Graphene Nanocomposites as Counter Electrode Materials for Platinum Free Dye-Sensitized Solar Cells (Dsscss). Mater. Lett. 2019, 256, 126651. [CrossRef]

14. Eslah, S.; Nouri, M. Synthesis and Characterization of Tungsten Trioxide/Polyaniline/Polyacrylonitrile Composite Nanofibers for Application as a Counter Electrode of Dsscs. Russ. J. Electrochem. 2019, 55, 291-304. [CrossRef]

15. Sowbakkiyavathi, E.S.; Murugadoss, V.; Sittaramane, R.; Angaiah, S. Development of Mose 2/Pani Composite Nanofibers as an Alternative to Pt Counter Electrode to Boost the Photoconversion Efficiency of Dye Sensitized Solar Cell. J. Solid State Electrochem. 2020, 24, 24-28. [CrossRef]

16. Chang, C.Y.; Anuratha, K.S.; Lin, Y.H.; Xiao, Y.; Hasin, P.; Lin, J.Y. Potential-Reversal Electrodeposited MoS 2 Thin Film as an Efficient Electrocatalytic Material for Bifacial Dye-Sensitized Solar Cells. Solar Energy 2020, 206, 163-170. [CrossRef]

17. Shahabuddin, S.; Sarih, N.M.; Ismail, F.H.; Shahid, M.M.; Huang, N.M. Synthesis of Chitosan Grafted-Polyaniline/Co $3 \mathrm{O}_{4}$ Nanocube Nanocomposites and Their Photocatalytic Activity toward Methylene Blue Dye Degradation. RSC Adv. 2015, 5, 83857-83867. [CrossRef] 
18. Varley, T.S.; Hirani, M.; Harrison, G.; Holt, K.B. Nanodiamond Surface Redox Chemistry: Influence of Physicochemical Properties on Catalytic Processes. Faraday Discuss. 2014, 172, 349-364. [CrossRef]

19. Song, L.; Wang, T.; Jing, W.; Xie, X.; Du, P.; Xiong, J. High Flexibility and Electrocatalytic Activity MoS $2 /$ Tic/Carbon Nanofibrous Film for Flexible Dye-Sensitized Solar Cell Based Photovoltaic Textile. Mater. Res. Bull. 2019, 118, 110522. [CrossRef] 